\title{
Epidemiological profile of Plasmodium ovale spp. imported from Africa to Anhui Province, China, 2012-2019
}

Tao Zhang ${ }^{1 \dagger}$, Shuqi Wang ${ }^{1 \dagger}$, Duoquan Wang ${ }^{2}$, Sarah Auburn ${ }^{3}$, Shenning $\mathrm{Lu}^{2}$, Xian Xu', Jingjing Jiang ${ }^{1}$,

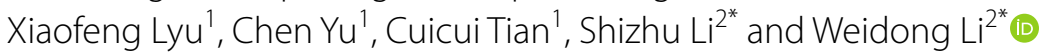

\begin{abstract}
Background: Although autochthonous malaria cases are no longer reported in Anhui Province, China, imported malaria has become a major health concern. The proportion of reported malaria cases caused by Plasmodium ovale spp. increased to levels higher than expected during 2012 to 2019, and showed two peaks, 19.69\% in 2015 and $19.35 \%$ in 2018 .
\end{abstract}

Methods: A case-based retrospective study was performed using data collected from the China Information System for Disease Control and Prevention (CISDCP) and Information System for Parasitic Disease Control and Prevention (ISPDCP) from 2012 to 2019 to assess the trends and differences between Plasmodium ovale curtisi (P. o. curtisi) and Plasmodium ovale wallikeri (P. o. wallikeri). Epidemiological characteristics were analyzed using descriptive statistics.

Results: Plasmodium o. curtisi and P. o. wallikeri were found to simultaneously circulate in 14 African countries. Among 128 patients infected with $P$. ovale spp., the proportion of co-infection cases was $10.16 \%$. Six cases of co-infection with $P$. ovale spp. and P. falciparum were noted, each presenting with two clinical attacks (the first attack was due to $P$. falciparum and the second was due to P. ovale spp.) at different intervals. Accurate identification of the infecting species was achieved among only $20.00 \%$ of cases of $P$. ovale spp. infection. At the reporting units, $32.17 \%$ and $6.96 \%$ of cases of $P$. ovale spp. infection were misdiagnosed as $P$. vivax and $P$. falciparum infections, respectively.

Conclusion: The present results indicate that the potential of $P$. ovale spp. to co-infect with other Plasmodium species has been previously underestimated, as is the incidence of $P$. ovale spp. in countries where malaria is endemic. P. $O$. curtisi may have a long latency period of $>3$ years and potentially cause residual foci, thus posing challenges to the elimination of malaria in P. ovale spp.-endemic areas. Considering the low rate of species identification, more sensitive point-of-care detection methods need to be developed for P. ovale spp. and introduced in non-endemic areas.

Keywords: Plasmodium ovale spp., Plasmodium ovale curtisi, Plasmodium ovale wallikeri, Imported malaria, Anhui province

\footnotetext{
*Correspondence: lisz@chinacdc.cn; ahcdclwd@163.com

tTao Zhang and Shuqi Wang contributed equally to the work

${ }^{2}$ National Institute of Parasitic Diseases, Chinese Center for Disease Control and Prevention, Shanghai 200025, China

Full list of author information is available at the end of the article
}

\section{Background}

Malaria remains a major global public health concern. In 2018, studies have estimated 228 million malaria cases, leading to 405,000 deaths worldwide [1]. Most malaria cases $(93 \%)$ and deaths (94\%) were in the World Health Organization (WHO) African Region, where

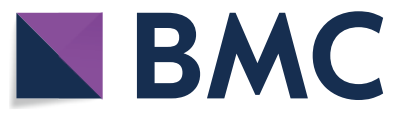

(c) The Author(s) 2021. This article is licensed under a Creative Commons Attribution 4.0 International License, which permits use, sharing, adaptation, distribution and reproduction in any medium or format, as long as you give appropriate credit to the original author(s) and the source, provide a link to the Creative Commons licence, and indicate if changes were made. The images or other third party material in this article are included in the article's Creative Commons licence, unless indicated otherwise in a credit line to the material. If material is not included in the article's Creative Commons licence and your intended use is not permitted by statutory regulation or exceeds the permitted use, you will need to obtain permission directly from the copyright holder. To view a copy of this licence, visit http://creativeco mmons.org/licenses/by/4.0/. The Creative Commons Public Domain Dedication waiver (http://creativecommons.org/publicdomain/ zero/1.0/) applies to the data made available in this article, unless otherwise stated in a credit line to the data. 
Plasmodium falciparum is the most prevalent malarial parasite, accounting for approximately $99.7 \%$ of cases [1].

In China, the National Malaria Elimination Action Plan (NMEAP) was launched in 2010, with the final objective of achieving elimination by 2020 [2, 3]. Owing to the introduction of the "1-3-7 model" to deliver and monitor the elimination process [4], local transmission of malaria in Anhui, a south-eastern province of China, was successfully interrupted [5]. No autochthonous cases have been reported since 2014. By 2019, Anhui province had been malaria-free for 6 years and passed the sub-national malaria elimination assessment. Nevertheless, with globalization and increased international movement, the province is facing a challenge from imported malaria cases.

In total, 935 imported cases of malaria were reported in Anhui Province from 2012 to 2019. Interestingly, the proportion of malaria caused by $P$. ovale spp. increased during this period to levels higher than expected. P. ovale spp. are two of the six Plasmodium species causing human transmission and was identified by Stevens in 1922 [6]. Sequence analysis recently revealed that $P$. ovale spp. essentially comprises two nonrecombining species, Plasmodium ovale curtisi (P. o. curtisi) and Plasmodium ovale wallikeri (P. o. wallikeri) [7]. Infection due to $P$. ovale spp. has generally been considered rare and limited by geographic distribution [8]. However, the availability of more sensitive PCR diagnosis methods has revealed that its geographic distribution is larger than previously speculated [7, 9]. Thus far, only a few epidemiological studies have investigated the respective dynamics of two sympatric species of $P$. ovale spp. and marked knowledge gaps exist. In the present study, a case-based, retrospective, comparative analysis was performed to analyse the trends and differences between $P$. o. curtisi and $P . o$. wallikeri. An increase in the knowledge of the epidemiology of the $P$. ovale spp. would help develop more effective public health responses.

\section{Methods}

\section{Cases and sympatric species confirmation}

Individuals with a confirmed infection were defined as malaria cases (infections). Since the risk of malaria is high in China, each suspected case is mandatorily reported [10]. Thereafter, staff from the county-level Center collected whole blood samples of patients before antimalarial treatment, and samples were sent to the Malaria Diagnostic Reference Laboratory of Anhui Province. In the reference Laboratory, DNA was extracted using the QIAamp DNA Mini kit (QIAGEN Inc, Hilden, Germany) in accordance with the manufacturer's instructions. The final diagnosis was confirmed through microscopic examination of Giemsa-stained thick and thin blood films under an oil immersion lens at $1000 \times$ magnification, and/or via real-time PCR. Commercial real-time PCR Kits (Shanghai ZJ Bio-tech Co., Ltd, Shanghai, China) were used to distinguish Plasmodium species. PCR was performed in a $40-\mu \mathrm{L}$ reaction mixture $\backslash$ containing $35 \mu \mathrm{L}$ reaction mix, $0.4 \mu \mathrm{L}$ enzyme mix, $1 \mu \mathrm{L}$ internal control, and $4 \mu \mathrm{L}$ DNA template. The reaction conditions were as follows: $37{ }^{\circ} \mathrm{C}$ for $2 \mathrm{~min}$ and $94{ }^{\circ} \mathrm{C}$ for $2 \mathrm{~min}$, followed by 40 cycles at $93{ }^{\circ} \mathrm{C}$ for $15 \mathrm{~s}$ and $60{ }^{\circ} \mathrm{C}$ for $60 \mathrm{~s}$; if $P$. ovale spp. was detected upon species identification, commercial real-time PCR kits (Shanghai BioGerm Medical Biotechnology Co., Ltd, Shanghai, China) were used, designed by referring to a previous study [11], to distinguish between $P$. o. curtisi and $P$. o. wallikeri. Real-time PCR was performed in a $25-\mu \mathrm{L}$ reaction volume containing a $16-\mu \mathrm{L}$ reaction mix, $4 \mu \mathrm{L}$ Primers Probe OVA $(\mathrm{c} / \mathrm{w})$, and $5 \mu \mathrm{L}$ DNA template. The reaction conditions were as follows: $95^{\circ} \mathrm{C}$ for $5 \mathrm{~min}$, followed by 40 cycles at $95^{\circ} \mathrm{C}$ for $10 \mathrm{~s}$, and $55^{\circ} \mathrm{C}$ for $40 \mathrm{~s}$.

\section{Data collection}

Cases of infection acquired outside the country were defined as "imported" [12]. The basic clinical and epidemiological data of each case were obtained from the China Information System for Disease Control and Prevention (CISDCP) and the Information System for Parasitic Disease Control and Prevention (ISPDCP) - a subsystem of the CISDCP, which includes age, sex, occupation, travel history, usual residence, date of onset and diagnosis, symptoms, and prognosis. After the investigation, staff from the county-level Center completed an epidemiological report for disease control primarily to identify the origin of the infection and record other valuable information. In the study, the latency period was determined for each case of malaria, as previously reported, by subtracting the date of arrival in China from the date of symptom onset (the last possible point in time when parasites could have been introduced by the infectious Anopheles species. However, this is a minimum estimate [13-15].

\section{Data analysis}

All statistical tests were performed using SPSS version 17.0 (SPSS Inc., Chicago, IL, USA). MapInfo 15.0 (Pitney Bowes Inc., Troy, NY, USA) compiled a thematic map of geographic distribution. The one-sample Kolmogorov-Smirnov test was performed to assess the normality of the distribution of continuous variables. Normally distributed continuous variables are presented as mean \pm standard deviation values and non-normal variables were expressed as median and interquartile range (IQR) values. The means of two continuous, normally distributed variables were compared using independent 
samples Student's $t$-test. The Mann-Whitney U test was used to compare non-normal variables. Categorical data are presented as ratios and percentages. The differences in proportions were compared using Pearson chi-squared or Fisher's exact test, as appropriate. All statistical tests were considered significant with 2 -sided $\mathrm{p}$ value $<0.05$.

\section{Results}

\section{Epidemiological profile of imported malaria in Anhui} Province, 2012-2019

In total, 941 cases of imported malaria were reported in Anhui province from 2012 to 2019. Cross-checks of the patient identifiers revealed that 6 patients had 2 clinical episodes owing to different malarial parasites after returning to China. These patients were reported twice owing to different dates of onset. PCR confirmed that they were co-infections (all were $P$. falciparum coinfected with $P$. ovale spp.). In this study, six cases were recorded as co-infections in accordance with the second clinical episode, and the number of imported malaria cases decreased to 935. P. falciparum was the dominant species, accounting for 733 cases (78.4\%), followed by P. ovale spp. (115 cases, $12.30 \%)$, P. malariae (38 cases, 4.06\%), P. vivax (35 cases, 3.74\%), and co- infection (14 cases, $1.50 \%)$. Among 14 cases of co-infection, there were 12 cases of $P$. falciparum co-infected with $P$. ovale spp., one of $P$. falciparum with $P$. malariae, and one of $P$. malariae with $P$. ovale spp. The proportion of imported cases due to $P$. ovale spp. peaked in 2015 (19.69\%) and 2018 (19.35\%), and increased from 2012 to 2018 $\left(x^{2}=9.626, p=0.002\right.$, excluded 2019) (Fig. 1).

\section{Origin of imported cases of $P$. ovale spp.}

All 128 patients infected with $P$. ovale spp., including coinfections, were imported from 16 countries in Africa. In total, 127 (99.22\%) P. ovale spp. cases were successfully confirmed via PCR; however, an inadequate blood sample was obtained from one patient for PCR and was only confirmed as $P$. ovale spp. through microscopy. The top four countries of origin for these infections were Equatorial Guinea (24, 18.75\%), Angola (22, 17.19\%), Nigeria (18, 14.06\%), and Cameroon (12, 9.38\%) (Table 1). One individual, infected in Angola, had a co-infection of $P$. o. curtisi and P. o. wallikeri. Therefore, 129 P. ovale spp. isolates were included in the analysis. Except for Ethiopia and Uganda (only one case each), $P$. o. curtisi and $P$. $o$. wallikeri were simultaneously detected in all countries. The proportion of $P$. o. curtisi ranged from $39.13 \%$ to $66.67 \%$ (Fig. 2).

\section{The incidence of $P$. ovale spp. in the primary countries of origin}

In general, a high proportion of $P$. ovale spp. did not necessarily indicate a high incidence. In this study, we utilized the number of returnees (Anhui Statistical Yearbook, http://tjj.ah.gov.cn/ssah/qwfbjd/tjnj/index .html) from countries of infectious origin to estimate $P$. ovale spp. and P. falciparum incidence rates in the four main countries (Cameroon, Angola, Equatorial Guinea,

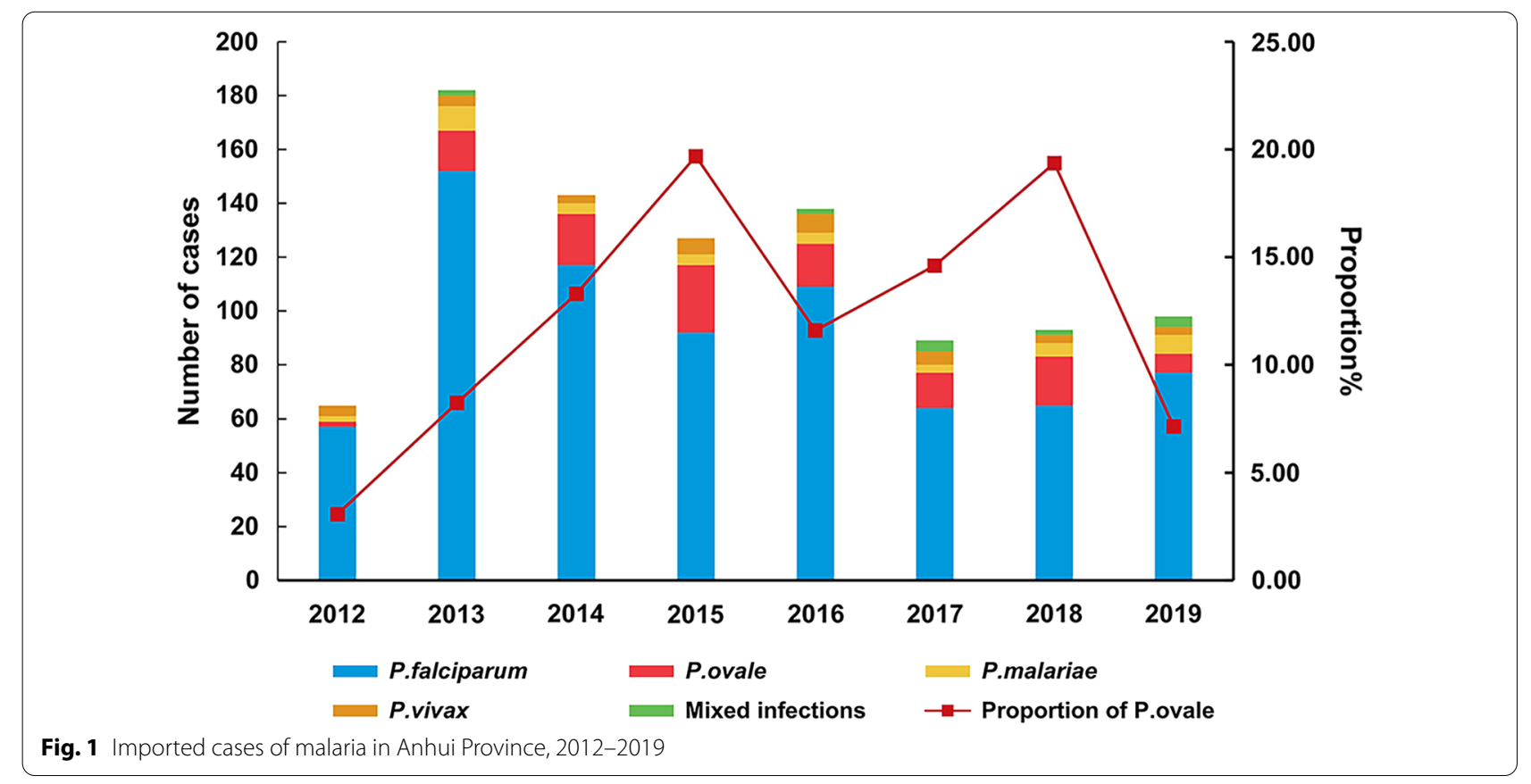


Table 1 Origin of imported $P$. ovale spp. in Anhui, 20122019

\begin{tabular}{|c|c|c|c|c|}
\hline \multirow[t]{2}{*}{ Country } & \multicolumn{2}{|c|}{ P. ovale curtisi } & \multicolumn{2}{|c|}{ P. ovale wallikeri } \\
\hline & $\mathbf{N}$ & $\%$ & $\mathrm{~N}$ & $\%$ \\
\hline Equatorial Guinea & 13 & 19.12 & 11 & 18.33 \\
\hline Nigeria & 11 & 16.18 & 7 & 11.67 \\
\hline Angola ${ }^{a}$ & 9 & 13.24 & 13 & 21.67 \\
\hline Cameroon & 6 & 8.82 & 6 & 10.00 \\
\hline Ghana & 5 & 7.35 & 3 & 5.00 \\
\hline Gabon & 4 & 5.88 & 3 & 5.00 \\
\hline Zambia & 3 & 4.41 & 2 & 3.33 \\
\hline Mozambique & 3 & 4.41 & 2 & 3.33 \\
\hline Ivory Coast & 3 & 4.41 & 4 & 6.67 \\
\hline Congo(Brazzaville) & 3 & 4.41 & 2 & 3.33 \\
\hline Malawi & 2 & 2.94 & 1 & 1.67 \\
\hline Guinea & 2 & 2.94 & 0 & 0.00 \\
\hline Congo(Kinshasa) & 2 & 2.94 & 3 & 5.00 \\
\hline Uganda & 1 & 1.47 & 0 & 0.00 \\
\hline Ethiopia & 1 & 1.47 & 0 & 0.00 \\
\hline Benin & 0 & 0.00 & 3 & 5.00 \\
\hline Total & 68 & 100.00 & 60 & 100.00 \\
\hline
\end{tabular}

a One case, infected in Angola, did not have enough blood available to discriminate subspecies of $P$. ovale spp.

and Nigeria). Using this method, the estimated average annual incidence rates of $P$. ovale spp. in Cameroon, Angola, Equatorial Guinea, and Nigeria were $2.48 \%$, $0.30 \%, 1.87 \%$, and $1.70 \%$, respectively. The average annual incidence rates of $P$. falciparum in Cameroon, Angola, Equatorial Guinea, and Nigeria were 9.90\%, 2.86\%, 8.86\%, and $8.11 \%$, respectively (Table 2).

\section{Epidemiological characteristics of $P$. o. curtisi and P. o. wallikeri}

Of 128 patients infected with $P$. ovale spp., 113 were single-species infections, as determined through PCR. Sixty-two $(62 / 113,54.87 \%)$ cases of $P$. o. curtisi and the remaining 51 cases of $P$. o. wallikeri $(51 / 113,45.13 \%)$ were noted. Among the other 15 cases, there were 13 cases of co-infections, 1 case with co-infection of $P$. o. curtisi and $P$. o. wallikeri, and 1 case without species confirmation. The median latency period for $P$. o. curtisi $(59.50 \mathrm{~d}$, IQR: 23.0-192.75) was slightly but not significantly longer than that of $P$. o. wallikeri (34 d, IQR: 12-112.50) $(P=0.070)$ (Fig. 3, Table 3). In the study, the longest latency period of $P$. ovale spp. was 1299 days, which was noted in an individual co-infected with $P$. o. curtisi and P. falciparum. Furthermore, no significant differences in sex, age, occupation, or history of malaria were observed between the P. o. curtisi and P. o. wallikeri groups (Table 3). In this study, co-infections of $P$. ovale spp. and other species, predominantly $P$. falciparum (12 cases) were reported in 13 cases in total. One case presented a co-infection of $P$. ovale spp. and $P$. malariae. The co-infection rate was $10.16 \%(13 / 128)$. Of all 12 co-infection of $P$. ovale spp. and $P$. falciparum cases, six had only one clinical episode and six had two clinical attacks, whereby the first attack was due to $P$. falciparum and the second attack was due to $P$. ovale spp.. The intervals between the 2 clinical episodes were $33,56,127,204,295$, and $1279 \mathrm{~d}$, for the six patients, respectively. Among patients with one clinical episode, 4 were infected with $P$. $o$. walliker $i$ and two were infected with $P$. o. curtisi; among patients with two clinical episodes, 3 cases were of $P$. o . wallikeri and 3 were $P$. o. curtisi.

\section{Diagnosis and clinical characterization of imported $P$. ovale spp. infections}

To analyze the diagnostic data on imported $P$. ovale spp. infections, individuals with a $P$. falciparum infection constituted the control group in the study. The median latency period of $P$. ovale spp. was 49 (IQR: 16.5-169.5) $\mathrm{d}$ and that of $P$. falciparum was 6 (IQR: 2-10) d; The median interval from onset to the first medical visit for P. ovale spp. was 1 (IQR: 0-3) d and that for P. falciparum was 1 (IQR: 0-2) d. The median interval from onset to the first medical visit to the diagnosis of $P$. ovale spp. infections was 1 (IQR: 0-3) d, while that for P. falciparum was 1 (IQR: 0-2) d. Based on the differences in the median intervals between the two species, $P$. ovale spp. had a significantly longer latency than $P$. falciparum $(\mathrm{Z}=-12.947, \mathrm{p}<0.001)$.

The parasite identification rates for $P$. ovale spp. and P. falciparum were comparable at $93.04 \%$ and $93.59 \%$, respectively. However, the rates of species identification were significantly different between $P$. ovale spp. and $P$. falciparum $\left(\chi^{2}=255.841, \mathrm{p}<0.001\right)$. Furthermore, among the 115 P. ovale spp. cases, only $20 \%$ of the cases (23/115) had an accurate species identification on microscopy (Table 4), while $32.17 \%$ (37/115) of cases were misdiagnosed as $P$. vivax, $6.96 \%(8 / 115)$ as $P$. falciparum. In the remaining $40.87 \%$ (47/115) of cases, species identification was not attempted, and only the parasite was identified (positive or negative finding). Among 733 P. falciparum cases, species identification revealed accurate results in $86.90 \%$ of cases $(637 / 733)$; however, results were not obtained for $11.87 \%(87 / 733)$ of cases. Only 9 cases were misdiagnosed with other malarial parasite species or with co-infections.

Of the 115 individuals with $P$. ovale spp. infection, common clinical symptoms included fever (99.13\%), chills (82.61\%), sweating (59.13\%), and headaches (55.65\%). Furthermore, $53.91 \%$ cases presented with typical clinical manifestations of malaria (chills, fever, and sweating). 


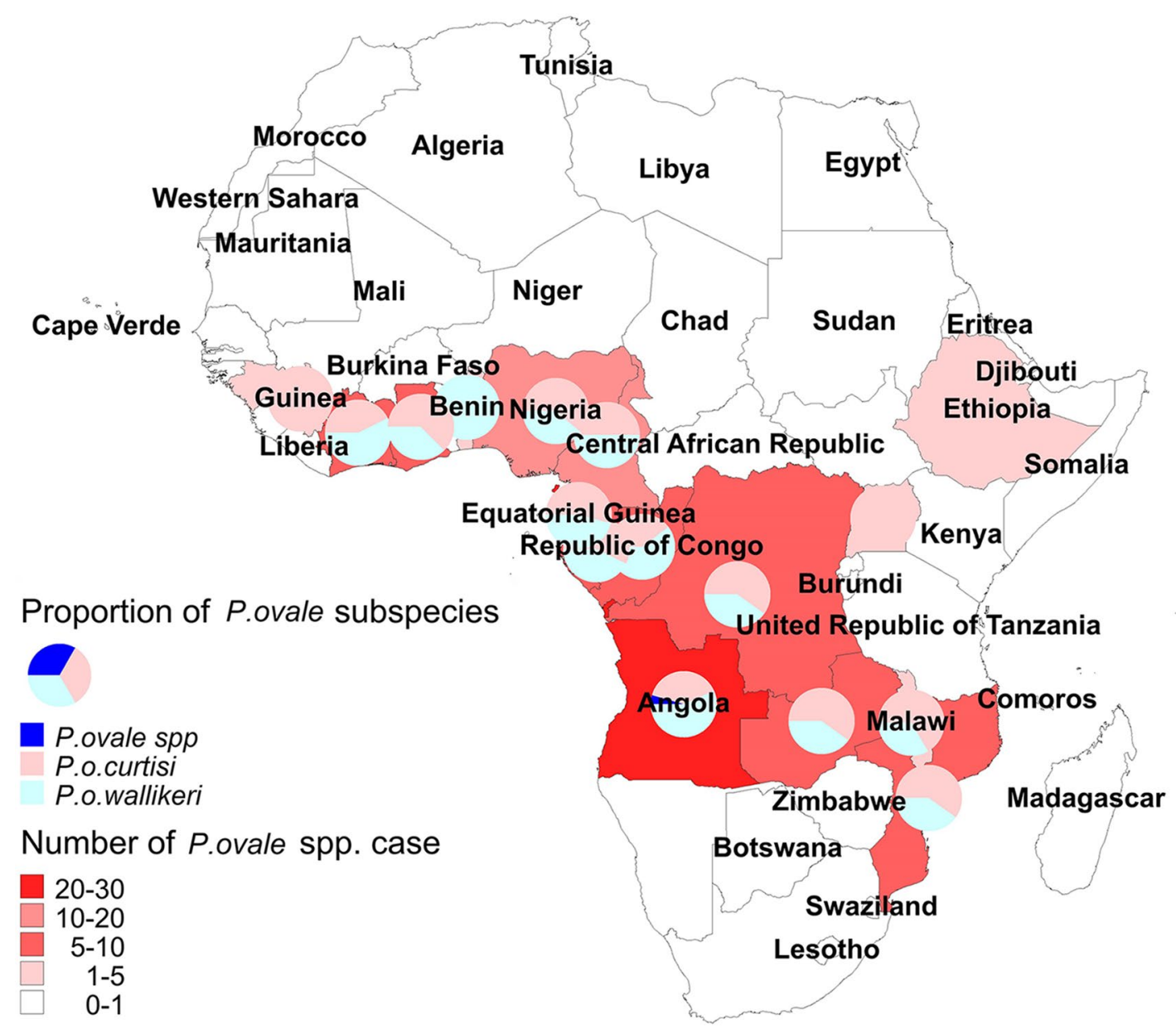

Fig. 2 Geographic distribution of the origin of imported cases of P. ovale in Africa, 2012-2019

Table 2 The incidence rates of $P$. ovale spp. and $P$. falciparum in the population returning from Africa to Anhui province

\begin{tabular}{|c|c|c|c|c|c|c|c|c|}
\hline \multirow[t]{2}{*}{ Year } & \multicolumn{4}{|l|}{ P. ovale spp. } & \multicolumn{4}{|l|}{ P. falciparum } \\
\hline & $\begin{array}{l}\text { Cameroon (\%, } \\
\left.\mathrm{n} / \mathrm{N}^{\mathrm{a}}\right)\end{array}$ & $\begin{array}{l}\text { Angola (\%, } \\
\mathrm{n} / \mathrm{N})\end{array}$ & $\begin{array}{l}\text { Equatorial } \\
\text { Guinea(\%, } \\
\mathrm{n} / \mathrm{N})\end{array}$ & $\begin{array}{l}\text { Nigeria (\%, } \\
n / N)\end{array}$ & $\begin{array}{l}\text { Cameroon (\%, } \\
\mathrm{n} / \mathrm{N})\end{array}$ & $\begin{array}{l}\text { Angola (\%, } \\
n / N)\end{array}$ & $\begin{array}{l}\text { Equatorial } \\
\text { Guinea(\%, } \\
n / N)\end{array}$ & $\begin{array}{l}\text { Nigeria (\%, } \\
\mathrm{n} / \mathrm{N})\end{array}$ \\
\hline 2012 & $0.00(0 / 64)$ & $0.00(0 / 3648)$ & $0.50(2 / 397)$ & $0.00(0 / 208)$ & $3.13(2 / 64)$ & $0.52(19 / 3648)$ & $4.03(16 / 397)$ & $2.88(6 / 208)$ \\
\hline 2013 & $2.3(1 / 44)$ & $0.14(2 / 1427)$ & $1.53(5 / 326)$ & $3.85(3 / 78)$ & $25.00(11 / 44)$ & $3.22(46 / 1427)$ & $10.74(35 / 326)$ & $23.08(18 / 78)$ \\
\hline 2014 & $0.00(0 / 60)$ & $0.51(3 / 593)$ & $2.65(7 / 265)$ & $2.65(4 / 176)$ & $11.67(7 / 60)$ & $4.72(28 / 593)$ & $12.08(32 / 265)$ & $7.39(13 / 176)$ \\
\hline 2015 & $2.15(2 / 93)$ & $1.02(5 / 489)$ & $5.38(6 / 112)$ & $0.00(0 / 205)$ & $1.08(1 / 93)$ & $7.16(35 / 489)$ & $10.71(12 / 112)$ & $5.37(11 / 205)$ \\
\hline 2016 & $4.73(4 / 85)$ & $1.21(3 / 249)$ & $0.00(0 / 74)$ & $3.41(5 / 147)$ & $12.94(11 / 85)$ & $16.47(41 / 249)$ & $5.41(4 / 74)$ & $7.48(11 / 147)$ \\
\hline 2017 & $4.76(2 / 42)$ & $1.00(1 / 101)$ & $3.88(2 / 52)$ & $5.00(5 / 100)$ & $11.90(5 / 42)$ & $12.87(13 / 101)$ & $11.54(6 / 52)$ & $10.00(10 / 100)$ \\
\hline 2018 & $5.71(1 / 18)$ & $3.69(6 / 163)$ & $18.18(1 / 6)$ & $0.00(0 / 87)$ & $16.67(3 / 18)$ & $5.52(9 / 163)$ & $66.67(4 / 6)$ & $13.79(12 / 87)$ \\
\hline $\begin{array}{l}\text { Average } \\
\text { annual inci- } \\
\text { dence (\%) }\end{array}$ & 2.48 & 0.30 & 1.87 & 1.70 & 9.90 & 2.86 & 8.86 & 8.11 \\
\hline
\end{tabular}

a $\mathrm{n}$ was the number of reported imported cases, and $\mathrm{N}$ was the number of people returning from the infectious origin countries in the same year

The incidence rate is underestimated because the number of people returning from Africa comes from official statistics, in which it is impossible to include all overseas laborers. Therefore, the results are for reference only 


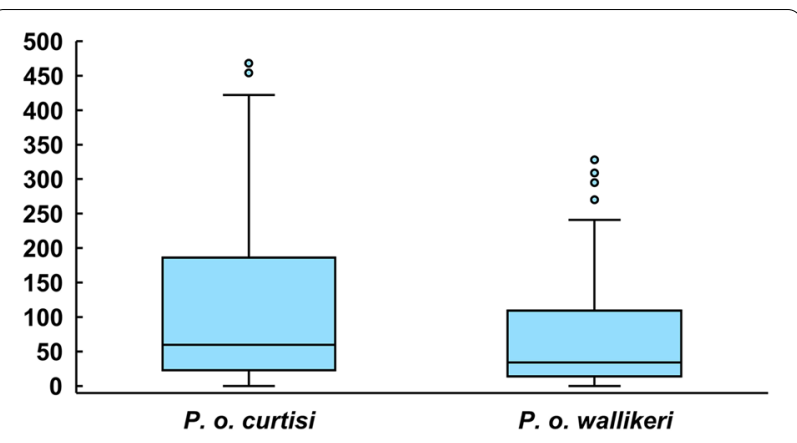

Fig. 3 Latency period for cases of P. ovale curtisi and P. ovale wallikeri in Anhui province, 2012-2019

\section{Discussion}

Although P. ovale spp. was identified by Stevens in 1922 [6], it has received limited attention in medical research. In 2010, two sympatric species, $P$. ovale curtisi and P. ovale wallikeri, were confirmed through sequence analysis [7]. However, few studies have described their epidemiological differences and have not reported consistent results. A recent study of imported cases in the United Kingdom reported that $P$. o. walliker $i$ had a shorter latency than $P$. $o$. curtisi [13], concurrent with another study on imported cases in Henan Province, China [14]. However, another study of imported cases in Jiangsu Province, China, did not report a significant difference in the latency period [15]. In this study, the difference in the latency period of two sympatric species was slightly short of statistical significance $(\mathrm{p}=0.070)$, suggesting that $P$. ovale wallikeri has a shorter latency periods; however, larger studies are needed to confirm these results at the statistical significance threshold. In the study, the longest latency period of $P$. ovale spp. was $1299 \mathrm{~d}$, which was noted in a case of a co-infection with $P$. o. curtisi and $P$. falciparum. These data are concurrent with the longest latency periods reported by Nolder et al. (1083 days) [13] and Zhou et al. (1265 days) [14]. The long latency periods of $P$. o. curtisi are worthy of attention, probably resulting in residual foci. It would be challenging to eliminate malaria in P. ovale spp.-endemic areas. Moreover, the concept of a latency period in $P$. ovale spp. has been challenged owing to limited experimental and clinical data supporting the hypnozoite model. Richter et al. reported that evidence was not sufficient to unequivocally demonstrate that $P$. ovale spp. hypnozoites are found in the human host [17]. Another review reported only 18 cases of relapse for $P$. ovale spp. in nearly 100 years [18]. However, a recent study provides direct evidence, using molecular analyses, of the reemergence of $P$. ovale curtisi strains, concurrent with the currently accepted relapse theory. Interestingly, relapse of $P$. ovale wallikeri infections was not noted in this study [19]. In this study, co-infections of $P$. ovale spp.

Table 3 Epidemiologic characteristics of imported two $P$. ovale subspecies

\begin{tabular}{|c|c|c|c|}
\hline Variables & P. ovale curtisi $(n=62) N(\%)$ & P. ovale wallikeri $(\mathrm{n}=51) \mathrm{N}(\%)$ & P value \\
\hline \multicolumn{4}{|l|}{ Sex ${ }^{a}$} \\
\hline Male & $61(98.4)$ & $51(100.0)$ & \multirow[t]{2}{*}{1.000} \\
\hline Female & $1(1.6)$ & $0(0.0)$ & \\
\hline Age(years), mean(SD) & $43.84 \pm 9.21$ & $43.53 \pm 7.82$ & 0.850 \\
\hline \multicolumn{4}{|l|}{ Occupation ${ }^{\mathrm{a}}$} \\
\hline Worker & $51(82.3)$ & $46(90.2)$ & \multirow[t]{3}{*}{0.463} \\
\hline Waiter & $7(11.3)$ & $3(5.9)$ & \\
\hline Other & $4(6.5)$ & $2(3.9)$ & \\
\hline \multicolumn{4}{|l|}{ Previous malaria } \\
\hline Yes & $44(71.0)$ & $41(80.4)$ & \multirow[t]{2}{*}{0.248} \\
\hline No & $18(29.0)$ & $10(19.6)$ & \\
\hline \multicolumn{4}{|l|}{ Duration of stay overseas $s^{a, b}$} \\
\hline$\leq 30$ & $0(0.0)$ & $1(2.3)$ & \multirow[t]{4}{*}{0.489} \\
\hline$\leq 180$ & $6(11.8)$ & $7(16.3)$ & \\
\hline$\leq 365$ & $10(19.6)$ & $11(25.6)$ & \\
\hline$>365$ & $35(68.6)$ & $24(55.8)$ & \\
\hline Latency period (days) ${ }^{c}$, median (IQR) & $59.50(23.0-192.75)$ & $34(12-112.50)$ & 0.070 \\
\hline
\end{tabular}


Table 4 The diagnosis of imported P. ovale and P. falciparum in Anhui, 2012-2019

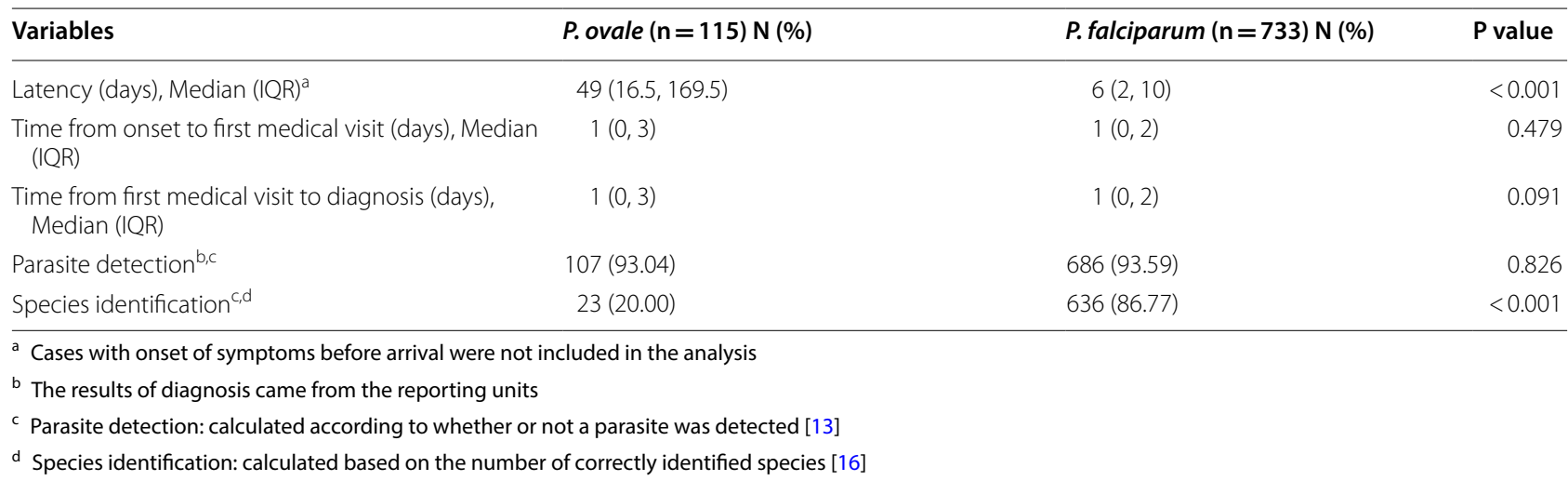

/ P. falciparum were noted, wherein two clinical attacks were triggered (the first attack due to $P$. falciparum, and the second due to $P$. ovale spp.). At the primary $P$. falciparum attack, patients were administered artemisininbased drugs without primaquine, the only effective drug against dormant liver parasites [20]. The second clinical attack due to $P$. ovale spp. occurred at a different interval. The remaining $P$. ovale spp. infections were treated with primaquine after diagnosis and no parasites reemerged in the blood samples (after the final diagnostic finding of the Malaria Diagnostic Reference Laboratory of Anhui Province feedback, $P$. ovale spp. were treated with primaquine to prevent relapse). Our findings potentially support the existence of hypnozoites of $P$. ovale spp. Moreover, the six cases of co-infections with two clinical episodes constitute the most important findings of this study. Identification of such co-infections is difficult in an endemic transmission setting. As $P$. ovale spp. infections are no endemic in China, if the present patient does not travel abroad again, it should be easy to diagnose coinfections. Furthermore, long-term observation would be required. In contrast, in endemic areas, especially in the high transmission setting, numerous cases of malaria were reported. In this context, if the interval between two clinical attacks was too long, it would be difficult to link these clinical events together, probably being considered independent. These six cases strongly suggest that the potential of $P$. ovale spp. to co-infect with other malarial species has been underestimated because cases as such were difficult to come across in cross-sectional surveys. Data from two recent studies provide evidence regarding this perspective $[21,22]$. It is worth noting that $71.0 \% P$. ovale curtisi and $80.4 \%$ P. ovale wallikeri are associated with a previous history of malaria, suggesting that more co-infections, presenting with two clinical attacks, may not be reported. Because our surveillance system only recorded the second clinical attack due to $P$. ovale spp. within the country, and not abroad, the proportion of $P$. ovale spp. may have increased. Nonetheless, more evidence is required. Mehlotra et al.reported that the higher overall prevalence of $P$. falciparum and $P$. vivax in a human population is associated with fewer mixed infections than expected [23], using point-prevalence data from 35 other studies. Based on our results, a potential explanation is that a moderate proportion of co-infections involving hypnozoites was undetected.

McKenzie and Bossert et al. reported that infection by one Plasmodium species does not reduce the susceptibility to infection by other species [24]. Therefore, an increase in the rate of co-infections suggests that the prevalence of $P$. ovale spp. has been underestimated. In this study, we examined the returnees from four African countries to estimate the incidence rates of $P$. ovale spp. and $P$. falciparum. Although it is only an estimate, with $P$. falciparum as a reference, the data suggest that the incidence of $P$. ovale spp. was higher than expected and a growing body of evidence supports this hypothesis [2527]. Considering the geographic distribution, our findings suggest that the two sympatric species, $P$. o. curtisi and $P$. o. wallikeri, have been circulating simultaneously in numerous Africa countries, concurrent with a previous study [28].

Owing to their similarities in morphology and life cycle, $P$. ovale spp. is easily and frequently misdiagnosed as a $P$. vivax infection $[29,30]$. In this study, only $20.00 \%$ of $P$. ovale spp. cases $(23 / 115)$ returned an accurate species identification on microscopic examination; $32.17 \%(37 / 115)$ of cases were misdiagnosed as $P$. vivax infections and $6.96 \%(8 / 115)$ of cases were misdiagnosed as $P$. falciparum infections. For the remaining $40.87 \%$ (47/115) of cases, species identification was not attempted, and only the results of parasite identification (positive or negative findings) were obtained. The success rates of species identification were significantly 
different between $P$. ovale spp. $(20.00 \%)$ and $P$. falciparum (86.77\%), Probably because two rapid diagnostic tests (Pf/pan, by Wondfo and by ACCESSBIO) highly sensitive to $P$. falciparum, but insensitive to $P$. ovale spp. [31, 32], have been used to provide parasite-based diagnosis in Anhui province since 2013. Misdiagnosis of $P$. ovale spp. infections as $P$. vivax or $P$. falciparum infections may have led to inappropriate case management measures and treatment regimens. Therefore, more sensitive point-of-care detection methods for $P$. ovale spp. need to be developed and introduced in nonendemic areas.

Our study has several limitations. First, it was a casebased, retrospective study, and was subject to recall bias. Second, some differences were simply beyond the threshold for statistical significance, requiring larger studies to confirm them. Lastly, the data on the use of prophylaxis are limited, thus potentially affecting the latency period of $P$. ovale spp.

\section{Conclusion}

In this study, 6 cases of co-infections of $P$. ovale spp./P. falciparum were noted, which presented as two clinical attacks, indicating that the potential of $P$. ovale spp. to co-infect with other malarial species has been previously underestimated. The incidence of $P$. ovale spp. has also probably been underestimated in these source countries where the disease is endemic. P. o. curtisi may have a long latency period of $>3$ years and potentially cause residual foci, thus posing challenges to the elimination of malaria in $P$. ovale spp.-endemic areas.

Given the low rate of species identification, more sensitive point-of-care detection methods need to be developed for $P$. ovale spp. and introduced in nonendemic areas.

\section{Acknowledgements}

We acknowledge staff members of the municipal and county Centers for Disease Control and Prevention of Anhui Province for their contribution to data collection.

\section{Authors' contributions}

$\mathrm{SL}$ and WL designed study; CY and CT contributed to the data analysis; $\mathrm{XL}$ and $J$ J were responsible for data collection; SW and JJ participated in the sample collection and performed the laboratory studies; DW and XX provided the administrative coordination; TZ and SW contributed to original draft; SA and $S L$ provided review and editing. coordination. All authors read and approved the final version of the manuscript.

\section{Funding}

National Science and Technology Key Projects (2016ZX10004222-004). The funders had no role in study design, data collection and analysis, decision to publish, or preparation of the manuscript.

\section{Availability of data and materials}

The datasets used and/or analysed during the current study are available from the corresponding author on reasonable request.

\section{Ethics approval and consent to participate}

This study was approved by the Institutional Ethics Committee of Anhui Provincial Center for Disease Control and Prevention. As the study was based on a retrospective review of disease notification data, informed consent was waived. The identifiers of patients were removed before analysis.

\section{Consent for publication}

Not applicable.

\section{Competing interests}

The authors declare that they have no competing interests.

\section{Author details}

${ }^{1}$ Anhui Provincial Center for Disease Control and Prevention, Hefei 230601, China. ${ }^{2}$ National Institute of Parasitic Diseases, Chinese Center for Disease Control and Prevention, Shanghai 200025, China. ${ }^{3}$ Global and Tropical Health Division, Menzies School of Health Research and Charles Darwin University, Darwin, NT, Australia.

Received: 18 August 2020 Accepted: 12 December 2020

Published online: 06 January 2021

References

1. WHO. World Malaria Report 2019. Geneva: World Health Organization; 2019.

2. Ministry of Health of the People's Republic of China. Action Plan of China Malaria Elimination (2010-2020). Beijing, China Ministry of Health of the People's Republic of China; 2010.

3. Feng J, Zhang L, Huang F, Yin JH, Tu H, Xia ZG, et al. Ready for malaria elimination: zero indigenous case reported in the People's Republic of China. Malar J. 2018;17:315.

4. Cao J, Sturrock HJ, Cotter C, Zhou S, Zhou H, Liu Y, et al. Communicating and monitoring surveillance and response activities for malaria elimination: China's"1-3-7" strategy. PLoS Med. 2014;11:e1001642.

5. Zhang T, Xu X, Jiang J, Yu C, Tian C, Xie Q, et al. Risk factors of severe imported malaria in Anhui province. China Acta Trop. 2019;197:104934.

6. Stephens WJW. A new malaria parasite of man. Ann Trop Med Parasitol. 1914:8:119-28.

7. Sutherland CJ, Tanomsing N, Nolder D, Oguike M, Jennison C, Pukrittayakamee $\mathrm{S}$, et al. Two nonrecombining sympatric forms of the human malaria parasite Plasmodium ovale occur globally. J Infect Dis. 2010;201:1544-50.

8. Mueller I, Zimmerman PA, Reeder JC. Plasmodium malariae and Plasmodium ovale-the "bashful" malaria parasites. Trends Parasitol. 2007;3:278-83

9. Fuehrer HP, Habler VE, Fally MA, Harl J, Starzengruber P, Swoboda P, et al. Plasmodium ovale in Bangladesh: genetic diversity and the first known evidence of the sympatric distribution of Plasmodium ovale curtisi and Plasmodium ovale wallikeri in southern Asia. Int J Parasitol. 2012:42:693-9.

10. Wang L, Wang Y, Jin S, Wu Z, Chin DP, Koplan JP, et al. Emergence and control of infectious diseases in China. Lancet. 2008:372:1598-605.

11. Bauffe F, Desplans J, Fraisier C, Parzy D. Real-time PCR assay for discrimination of Plasmodium ovale curtisi and Plasmodium ovale wallikeri in the Ivory Coast and in the Comoros Islands. Malar J. 2012;11:307.

12. WHO. WHO malaria terminology. Geneva: World Health Organization; 2016.

13. Nolder D, Oguike MC, Maxwell-Scott H, Niyazi HA, Smith V, Chiodini PL, et al. An observational study of malaria in British travellers: Plasmodium ovale wallikeri and Plasmodium ovale curtisi differ significantly in the duration of latency. BMJ Open. 2013:3:e002711.

14. Zhou R, Li S, Zhao Y, Yang C, Liu Y, Qian D, et al. Characterization of Plasmodium ovale spp. imported from Africa to Henan Province, China. Sci Rep. 2019;9:2191.

15. Cao Y, Wang W, Liu Y, Cotter C, Zhou H, Zhu G, et al. The increasing importance of Plasmodium ovale and Plasmodium malariae in a malaria elimination setting: an observational study of imported cases in Jiangsu Province, China, 2011-2014. Malar J. 2016;15:459.

16. WHO. Malaria microscopy quality assurance manual version 2. Geneva: World Health Organization; 2016. 
17. Richter J, Franken G, Mehlhorn H, Labisch A, Haussinger D. What is the evidence for the existence of Plasmodium ovale hypnozoites? Parasitol Res. 2010;107:1285-90.

18. Groger M, Fischer HS, Veletzky L, Lalremruata A, Ramharter M. A systematic review of the clinical presentation, treatment and relapse characteristics of human Plasmodium ovale malaria. Malar J. 2017;16:112.

19. Groger M, Veletzky L, Lalremruata A, Cattaneo C, Mischlinger J, Manego Zoleko R, et al. Prospective clinical and molecular evaluation of potential Plasmodium ovale curtisi and wallikeri relapses in a high-transmission Setting. Clin Infect Dis. 2019;69:2119-26.

20. WHO. Confronting Plasmodium vivax malaria. Geneva: World Health Organization; 2016.

21. Groger M, Veletzky L, Lalremruata A, Cattaneo C, Mischlinger J, ZolekoManego $R$, et al. Prospective clinical trial assessing species-specific efficacy of artemether-lumefantrine for the treatment of Plasmodium malariae, Plasmodium ovale, and mixed Plasmodium malaria in Gabon. Antimicrob Agents Chemother. 2018;62:e01758-e1817.

22. Manego RZ, Mombo-Ngoma G, Witte M, Held J, Gmeiner M, Gebru T, et al. Demography, maternal health and the epidemiology of malaria and other major infectious diseases in the rural department TsambaMagotsi, Ngounie Province, in central African Gabon. BMC Public Health. 2017;17:130.

23. Mehlotra RK, Kasehagen L, Baisor M, Lorry K, Kazura JW, Bockarie MJ, et al. Malaria infections are randomly distributed in diverse holoendemic areas of Papua New Guinea. Am J Trop Med Hyg. 2002;67:555-62.

24. McKenzie FE, Bossert WH. Mixed-species Plasmodium infections of humans. J Parasitol. 1997:83:593-600.

25. Trape J-F, Tall A, Sokhna C, Ly AB, Diagne N, Ndiath O, et al. The rise and fall of malaria in a west African rural community, Dielmo, Senegal, from 1990 to 2012: a 22 year longitudinal study. Lancet Infect Dis. 2014;14:476-88.

26. Roucher C, Rogier C, Sokhna C, Tall A, Trape JF. A 20-year longitudinal study of Plasmodium ovale and Plasmodium malariae prevalence and morbidity in a West African population. PLoS ONE. 2014;9:e87169.

27. Doderer-Lang C, Atchade PS, Meckert L, Haar E, Perrotey S, Filisetti D, et al. The ears of the African elephant: unexpected high seroprevalence of Plasmodium ovale and Plasmodium malariae in healthy populations in Western Africa. Malar J. 2014;13:240.

28. Oguike MC, Betson M, Burke M, Nolder D, Stothard JR, Kleinschmidt I, et al. Plasmodium ovale curtisi and Plasmodium ovale wallikeri circulate simultaneously in African communities. Int J Parasitol. 2011;41:677-83.

29. Yao LN, Zhang LL, Ruan W, Chen HL, Lu QY, Yang TT. Species identification in 5 imported cases previously diagnosed as Vivax malaria by parasitological and nested PCR techniques (in Chinese). Zhongguo Ji Sheng Chong Xue Yu Ji Sheng Chong Bing Za Zhi. 2013;31:221-4.

30. Chavatte JM, Tan SB, Snounou G, Lin RT. Molecular characterization of misidentified Plasmodium ovale imported cases in Singapore. Malar J. 2015; 14:454.

31. Tang J, Tang F, Zhu H, Lu F, Xu S, Cao Y, et al. Assessment of false negative rates of lactate dehydrogenase-based malaria rapid diagnostic tests for Plasmodium ovale detection. PLoS Negl Trop Dis. 2019;13:e0007254.

32. Mukkala AN, Kwan J, Lau R, Harris D, Kain D, Boggild AK. An update on malaria rapid diagnostic tests. Curr Infect Dis Rep. 2018;20:49.

\section{Publisher's Note}

Springer Nature remains neutral with regard to jurisdictional claims in published maps and institutional affiliations.
Ready to submit your research? Choose BMC and benefit from:

- fast, convenient online submission

- thorough peer review by experienced researchers in your field

- rapid publication on acceptance

- support for research data, including large and complex data types

- gold Open Access which fosters wider collaboration and increased citations

- maximum visibility for your research: over 100M website views per year

At BMC, research is always in progress.

Learn more biomedcentral.com/submissions 